\title{
Demographic and medical factors affecting short-term changes in subjective evaluation of asthma control in adolescents
}

\author{
Anna Bednarek ${ }^{1}$, Anna Bodajko-Grochowska ${ }^{2}$, Małgorzata Bartkowiak-Emeryk ${ }^{3}$, Robert Klepacz ${ }^{4}$, Janusz Ciółkowski ${ }^{5}$, \\ Danuta Zarzycka ${ }^{1}$, Andrzej Emeryk ${ }^{2}$ \\ ${ }^{1}$ Department of Pediatric Nursing, Faculty of Nursing and Health Science, Medical University of Lublin, Lublin, Poland \\ 2Department of Pulmonary Diseases and Pediatric Rheumatology, University Children's Hospital, Lublin, Poland \\ ${ }^{3}$ Department of Immunology and Immunotherapy, Medical University of Lublin, Lublin, Poland \\ ${ }^{4}$ Department of Clinical Pathomorphology, Medical University of Lublin, Lublin, Poland \\ ${ }^{5}$ Allergy Clinic, Independent Public Hospital, Lesko, Poland
}

Adv Dermatol Allergol 2018; XXXV (3): 259-266

DOI: https://doi.org/10.5114/ada.2018.76221

\begin{abstract}
Introduction: Asthma control is an important measure of disease stabilization, which is linked to the treatment and lifestyle recommendations.

Aim: To assess the impact of selected factors on asthma control in adolescents, as assessed using the Asthma Control Test $\left(\mathrm{ACT}^{\mathrm{TM}}\right)$.

Material and methods: The prospective study included 100 asthma patients aged between 12 and 19. Asthma was assessed in three consecutive follow-up visits spaced 3 months apart, using the standardized ACT $^{\text {TM }}$ questionnaire. Results: Asthma was fully controlled (ACT score $=25$ points) in more than half of the patients in all follow-up visits (53.0\%, 54.0\%, and 56.0\%, respectively). More than one third of the participants scored between 20 and 24 points ( $37.0 \%$ vs. $39.0 \%$ vs. $40.0 \%$ ). A minority of patients had uncontrolled asthma (scores below 20 ), and the group consistently diminished in subsequent visits (10\% vs. $7 \%$ vs. $4 \%$ ). Uncontrolled asthma was found significantly more often in female patients $(33.33 \% ; p<0.001)$ and those living in rural areas $(20.59 \% ; p<0.01)$. Treatment with a combination of inhaled corticosteroids (ICS) and LABAs was associated with worse asthma control (14.81\%; $p<0.05)$. Better asthma control was found in patients with a family history of allergies $(73.85 \%$ vs. $75.38 \%$ vs. $78.46 \% ; p<0.001)$ and in those with concurrent allergies (66.67\% vs. $68.00 \%$ vs. $70.67 \% ; p<0.001)$.

Conclusions: Asthma control in adolescents differs by sex and residence. Concurrent allergies and family history of allergies improve asthma self-control in adolescents.
\end{abstract}

Key words: asthma, adolescents, asthma control, Asthma Control Test.

\section{Introduction}

Asthma is the most common chronic respiratory disease in children and adolescents in most developed countries [1]. International studies indicate that asthma affects between $5 \%$ and $15 \%$ of population in the developing age, with numerous reports of a high incidence of asthma and allergic rhinitis in the last several decades [2-4]. An ECAP study (Epidemiology of Allergies in Poland) conducted between 2007 and 2008 in 9 regions of Poland showed that asthma affects $2-7 \%$ of children aged 6 and 7 , and $4-10 \%$ of children aged 13 and 14 . Findings included significant differences between regions in terms of asthma severity and a higher prevalence in children living in urban areas, compared to those living in rural areas. The increase in asthma diagnoses is estimated at 0.4-0.7 annually, which allows one to estimate the rise in asthma prevalence in Poland at 5\% per decade [5-7].

The complex etiology of asthma, as well as its longterm and unpredictable clinical course, necessitate constant monitoring of its symptoms, as well as modifying treatment to prevent disease progression and permanent damage. The identification of factors affecting asthma control and the risk of hospitalization, as well as the ability to live an active life, are key measures of management effectiveness [8-11].

Address for correspondence: Anna Bednarek, University Children' Hospital, 6 Professor Antoni Gębala St, 20-093 Lublin, Poland, phone: +48 8171853 75, +48 607607 115, e-mail: bednarekanna@o2.pl Received: 10.11.2016, accepted: 22.03.2017. 
Guidelines on asthma education and prevention highlight asthma control as a matter of special importance. Asthma control is the optimum criterion for asthma grading, which is mainly linked to treatment recommendations. The current Global Initiative for Asthma (GINA) 2016 guidelines define, based among other factors on clinical parameters and forced expiratory volume in $1 \mathrm{~s}\left(\mathrm{FEV}_{1}\right)$ or $\mathrm{FEV}_{1} /$ forced vital capacity (FCV)\%, three asthma control levels: full control, partial control, and no control. In healthy children, the obtained values of $\mathrm{FEV}_{1} / \mathrm{FCV} \%$ and $\mathrm{FEV}_{1} \%$ should be within the range of $80-120 \%$ predicted, between -1.645 SD and +1.645 SD from the predicted or between 5 and 95 percentile [12-17].

In daily practice, asthma control tests are especially useful, quickly providing vital information on the patient's health. Until recently, most questionnaires in use were very extensive and required assistance from qualified medical personnel to complete them. In 2004, the standardized Asthma Control Test (АСТ ${ }^{\mathrm{TM}}$ ) was proposed for evaluating asthma control in patients above 12 years of age. The questionnaire enables adequate evaluation of asthma control as it is reliable, accurate, and multidimensional, and is still easily completed by the patient [18]. The ACT comprises 5 questions regarding limitations in the activity imposed by the illness, shortness of breath, sleep disorders, and the need for rescue medication. Each answer is rated from 1 to 5 points. A score of 25 indicates fully controlled asthma, scores of 20-24 indicate partially controlled asthma, and scores of 19 or lower - uncontrolled asthma. The test results should be considered in subsequent treatment interventions and recommendations regarding the patient's daily functioning $[19,20]$.

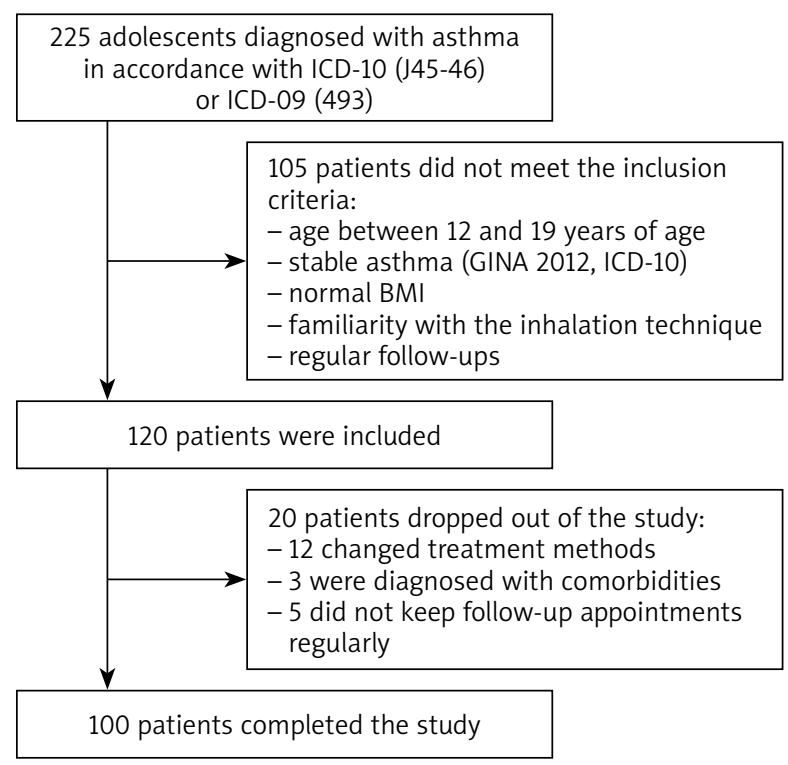

Figure 1. Study group selection process

\section{Aim}

The purpose of the study was to assess the impact of selected factors on asthma control in adolescents, based on ACT scores.

\section{Material and methods}

The study was performed at the allergy clinic of the Independent Public Hospital in Lesko, Podkarpackie Province, Poland. The Asthma Control Test (ACT ${ }^{\mathrm{TM}}$ ) is increasingly administered as a standard procedure for follow-up visits for patients aged 12 and above, including adults.

At the preparatory stage, the medical records of 225 asthma patients were reviewed in September 2013. One hundred and twenty patients meeting all the inclusion criteria were selected to participate in the 9-month prospective study. The inclusion criteria were: age between 12 and 19; stable asthma diagnosed at least 1 year beforehand, in accordance with ICD-10 (J45-46) or ICD-9 (493) and the GINA 2012 criteria; familiarity with the medication inhalation technique; keeping follow-up appointments; and normal body weight (body mass index (BMI) between 18.5 and $24.9 \mathrm{~kg} / \mathrm{m}^{2}$, and percentile rank between 10 and 90 ). The patients were evaluated in 3 follow-up visits, spaced 3 months \pm 7 days apart. Of the 120 participants, 20 dropped out of the study: 12 due to a change in treatment methods, 3 due to comorbidities, and 5 due to irregularities in follow-up appointment keeping. The final analysis included 100 patients who completed the study (Figure 1). The study was approved by the Bioethics Committee of the Lublin Medical University and the Allergy Clinic Director. Consent was obtained from the patients and their parents.

\section{Statistical analysis}

The research instrument used was the standardized ACT ${ }^{\mathrm{TM}}$ questionnaire. In addition, during each visit, spirometry examination was performed. The parameter values analyzed were shown as numbers and percentages. The relationships between the studied characteristics were evaluated using the $\chi^{2}$ test for independence. For FEV/FCV\% ratio, the following were calculated: the range of values (min., max.), arithmetic mean (M), standard deviation (SD), median (Me) and percentiles (25\%, $75 \%$ ). Normal distribution of FEV/FCV\% was estimated with Shapiro-Wilk W test. The significance of differences between individual visits was assessed with Friedman ANOVA test, and the significance of differences for FEV/ FCV\% depending on asthma control on the basis of the ACT was assessed with Kruskal-Wallis ANOVA test. Differences at $p<0.05$ were considered statistically significant. Statistical analyses were performed using Statistica 10.0 software (StatSoft, Inc., USA). 


\section{Results}

The study group included patients between 12 and 19 years of age (mean age: $15.07 \pm 2.17$ years), $76 \%$ were males and $24 \%$ females (Table 1). Sixty-six percent of participants lived in rural areas. $70 \%$ were found to have lgEdependent asthma, based on a positive skin allergy test for one or more of the following allergens: mold, mixed grass pollens, hazel pollen, birch pollen, alder pollen, cat and dog hair. Family history was positive for atopy in $65 \%$ of patients. Fifty-eight percent of participants had concurrent allergic rhinitis, and $17 \%$ - atopic dermatitis. Seventy-three percent were treated with inhaled corticosteroids (ICS), $27 \%$ with a combination of ICS and long-acting $\beta_{2}$ adrenoceptor agonists (LABAs), and 35\% were additionally undergoing allergen immunotherapy. All patients used short-acting $\beta_{2}$ adrenoceptor agonists (SABAs) as rescue medication. Patients were treated without changes throughout the analysis period.

More than half of the patients achieved ACT scores of 25 points, indicating fully controlled asthma, at each follow-up visit (V1 vs. V2 vs. V3) (Table 2). More than one third of the participants scored between 20 and 24 points (37.0\% vs. $39.0 \%$ vs. $40.0 \%$ ). A minority of patients had uncontrolled asthma (scores below 20 points). Asthma self-control did not significantly change in the analysis period.

The results of the spirometry test (Table 3 ) showed that teenagers with mild asthma $\left(\mathrm{FEV}_{1} / \mathrm{FCV} \%\right.$ between 70-80\% predicted) were participating in the study. The highest average value of $F E V_{1} / F C V \%$ was recorded on visit 2 , while the lowest on visit $1(p<0.001)$. At the time of enrollment in 53 respondents who scored 25 points in ACT test and in 37 with a score of 20-24 points, the $\mathrm{FEV}_{1}$ I FCV\% ratio remained as 78.07-80.18\%; in further 10 with $\mathrm{ACT}<20$ points this ratio was $78.07 \%$.
Table 1. Asthma patients' characteristics

\begin{tabular}{ll}
\hline Parameter & Result \\
\hline Age (min.-max.) [years] & $12-19$ \\
\hline $12-15, n(\%)$ & $57(57)$ \\
\hline$>15-19, n(\%)$ & $43(43)$ \\
\hline Gender, $n(\%):$ & $76(76)$ \\
\hline Male & $24(24)$ \\
\hline Female & \\
\hline Residence, $n(\%):$ & $34(34)$ \\
\hline Urban & $66(66)$ \\
\hline Rural
\end{tabular}

Family history of allergies, $n$ (\%):

\begin{tabular}{ll}
\hline Yes & $65(65)$ \\
\hline No & $35(35)$
\end{tabular}

Asthma phenotype, $n$ (\%):

\begin{tabular}{ll}
\hline IgE-dependent & $70(70)$ \\
\hline Non-lgE-dependent & $30(30)$ \\
\hline
\end{tabular}

Concurrent allergies, $n$ (\%):

\begin{tabular}{lc}
\hline Allergic rhinitis & $58(58)$ \\
\hline Atopic dermatitis & $17(17)$
\end{tabular}

Asthma treatment, $n$ (\%):

\begin{tabular}{lc}
\hline Inhaled GCs & $73(73)$ \\
\hline SABAs & $100(100)$ \\
\hline Inhaled GCs + LABAs & $27(27)$ \\
\hline
\end{tabular}

Table 2. Overall ACT result for the asthma patients

\begin{tabular}{lccc}
\hline Score: asthma control & & Visit & Statistical parameters \\
\cline { 2 - 4 } & V1 & V2 & V3 \\
\hline 25 points & $53(53 \%)$ & $54(54 \%)$ & $56(56 \%)$ \\
\hline $20-24$ points & $37(37 \%)$ & $39(39 \%)$ & $40(40 \%)$ \\
\hline 20 points & $10(10 \%)$ & $7(7 \%)$ & $4(4 \%)$ \\
\hline Mean score \pm SD & $22.73 \pm 3.33$ & $23.18 \pm 2.96$ & $23.42 \pm 2.52$ \\
\hline
\end{tabular}

Table 3. The value of $\mathrm{FEV}_{1} / \mathrm{FCV} \%$ ratio on subsequent visits

\begin{tabular}{|c|c|c|c|c|c|c|c|c|c|}
\hline Visit & $N$ & Min. & Max. & Mean & SD & Median & $25 \%$ & $75 \%$ & $P$-value \\
\hline V1 & 100 & 78.07 & 80.18 & 78.47 & 0.83 & 78.07 & 78.07 & 78.07 & \multirow{3}{*}{$<0.001$} \\
\hline V2 & 100 & 78.07 & 82.29 & 79.97 & 1.67 & 80.18 & 78.07 & 82.29 & \\
\hline V3 & 100 & 77.02 & 84.40 & 79.42 & 2.85 & 78.07 & 77.02 & 80.18 & \\
\hline
\end{tabular}


During visit V2 in 54 patients who scored 25 points in ACT test, $\mathrm{FEV}_{1} / \mathrm{FVC} \%$ of $78.07-82.29 \%$ was observed, while in 7 patients with a score of ACT $<20$ points the $\mathrm{FEV}_{1} /$ FVC\% ratio was $79.13 \%$. When analyzing the results of spirometry tests on visit $\mathrm{V} 3$ it was noted that in subjects with ACT equal to 25 points, Tiffeneau index was slightly higher and amounted to $78.07-84.4 \%$, while in adolescents with ACT $<20$ points the values reached $77.02 \%$. These differences were statistically significant $(p<0.001)$.

A statistically significant correlation was found (Table 4) between patients' sex and overall ACT results in visits V1 $\left(\chi^{2}=22.32 ; p<0.01\right)$ and V2 $\left(\chi^{2}=11.42 ; p<0.01\right)$. At these visits, significantly more girls than boys had un- controlled asthma. During the third visit, no significant differences in ACT results were found between male and female patients. No statistically significant correlations were found between patient age and the overall ACT results in the three follow-up visits. A statistically significant correlation was, however, found between the patients' residence and the overall ACT result - at V1 only. Uncontrolled asthma was more common in youths from rural areas. In the two remaining visits, residence did not determine the overall ACT result.

A statistically significant difference was found between the treatment used and the overall ACT results during visits V2 and V3 (Figure 2). Patients treated with

Table 4. Selected demographic characteristics (age, sex, residence) and asthma control as assessed using the ACT

\begin{tabular}{|c|c|c|c|c|}
\hline Sex & $\begin{array}{l}\text { ACT score } \\
\text { (points) }\end{array}$ & $\begin{array}{l}\text { Boys } \\
n(\%)\end{array}$ & $\begin{array}{l}\text { Girls } \\
n(\%)\end{array}$ & $\begin{array}{c}\text { Statistical } \\
\text { parameters }\end{array}$ \\
\hline \multirow[t]{3}{*}{ V1 } & 25 & $40(52.63)$ & $13(54.17)$ & \multirow{3}{*}{$\begin{array}{l}\chi^{2}=22.32 \\
p<0.001\end{array}$} \\
\hline & $20-24$ & $34(44.74)$ & $3(12.5)$ & \\
\hline & $<20$ & $2(2.63)$ & $8(33.33)$ & \\
\hline \multirow[t]{3}{*}{ V2 } & 25 & $40(52.63)$ & $14(58.33)$ & \multirow{3}{*}{$\begin{array}{c}\chi^{2}=11.42 \\
p<0.01\end{array}$} \\
\hline & $20-24$ & $34(44.74)$ & $5(20.83)$ & \\
\hline & $<20$ & $2(2.63)$ & $5(20.83)$ & \\
\hline \multirow[t]{3}{*}{ V3 } & 25 & $40(52.63)$ & $16(66.67)$ & \multirow{3}{*}{$\begin{array}{c}\chi^{2}=3.90 \\
p=0.1422\end{array}$} \\
\hline & $20-24$ & $34(44.74)$ & $6(25)$ & \\
\hline & $<20$ & $2(2.63)$ & $2(8.33)$ & \\
\hline Age & $\begin{array}{l}\text { ACT score } \\
\text { (points) }\end{array}$ & $\begin{array}{c}\leq 15 \text { years old } \\
n(\%)\end{array}$ & $\begin{array}{c}>15 \text { years old } \\
n(\%)\end{array}$ & $\begin{array}{c}\text { Statistical } \\
\text { parameters }\end{array}$ \\
\hline \multirow[t]{3}{*}{ V1 } & 25 & 33 (57.89) & $20(46.51)$ & \multirow{3}{*}{$\begin{array}{c}\chi^{2}=1.28 \\
p=0.5209\end{array}$} \\
\hline & $20-24$ & 19 (33.33) & $18(41.86)$ & \\
\hline & $<20$ & $5(8.77)$ & $5(11.63)$ & \\
\hline \multirow[t]{3}{*}{ V2 } & 25 & $34(59.65)$ & $20(46.51)$ & \multirow{3}{*}{$\begin{array}{c}\chi^{2}=3.25 \\
p=0.1969\end{array}$} \\
\hline & $20-24$ & $18(31.58)$ & $21(48.84)$ & \\
\hline & $<20$ & $5(8.77)$ & $2(4.65)$ & \\
\hline \multirow[t]{3}{*}{ V3 } & 25 & $36(63.16)$ & $20(46.51)$ & \multirow{3}{*}{$\begin{array}{c}\chi^{2}=2.77 \\
p=0.2509\end{array}$} \\
\hline & $20-24$ & 19 (33.33) & $21(48.84)$ & \\
\hline & $<20$ & $2(3.51)$ & $2(4.65)$ & \\
\hline Residence & $\begin{array}{l}\text { ACT score } \\
\text { (points) }\end{array}$ & $\begin{array}{l}\text { Rural } \\
n(\%)\end{array}$ & $\begin{array}{l}\text { Urban } \\
n(\%)\end{array}$ & $\begin{array}{c}\text { Statistical } \\
\text { parameters }\end{array}$ \\
\hline \multirow[t]{3}{*}{ V1 } & 25 & $33(50.00)$ & $20(58.82)$ & \multirow{3}{*}{$\begin{array}{c}\chi^{2}=9.86 \\
p<0.01\end{array}$} \\
\hline & $20-24$ & $30(45.45)$ & $7(20.59)$ & \\
\hline & $<20$ & $3(4.55)$ & $7(20.59)$ & \\
\hline \multirow[t]{3}{*}{ V2 } & 25 & $33(50.00)$ & $21(61.76)$ & \multirow{3}{*}{$\begin{array}{c}\chi^{2}=4.34 \\
p=0.1954\end{array}$} \\
\hline & $20-24$ & $30(45.45)$ & $9(26.47)$ & \\
\hline & $<20$ & $3(4.55)$ & 4 (11.76) & \\
\hline \multirow[t]{3}{*}{ V3 } & 25 & $33(50.00)$ & $23(67.65)$ & \multirow{3}{*}{$\begin{array}{c}\chi^{2}=2.84 \\
p=0.2422\end{array}$} \\
\hline & $20-24$ & $30(45.45)$ & $10(29.41)$ & \\
\hline & $<20$ & $3(4.55)$ & $1(2.94)$ & \\
\hline
\end{tabular}


A

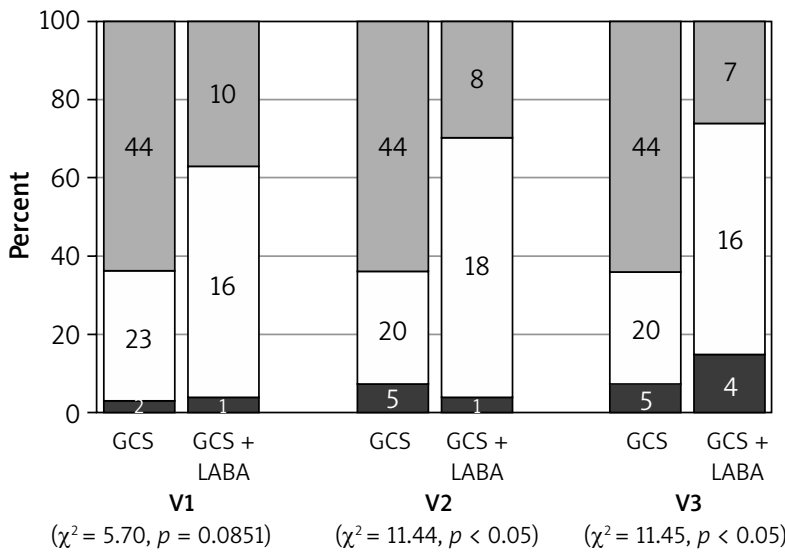

C

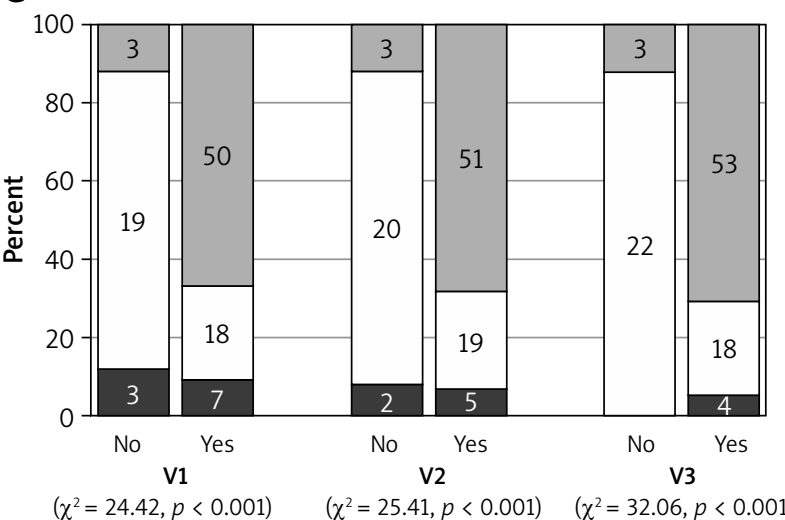

E

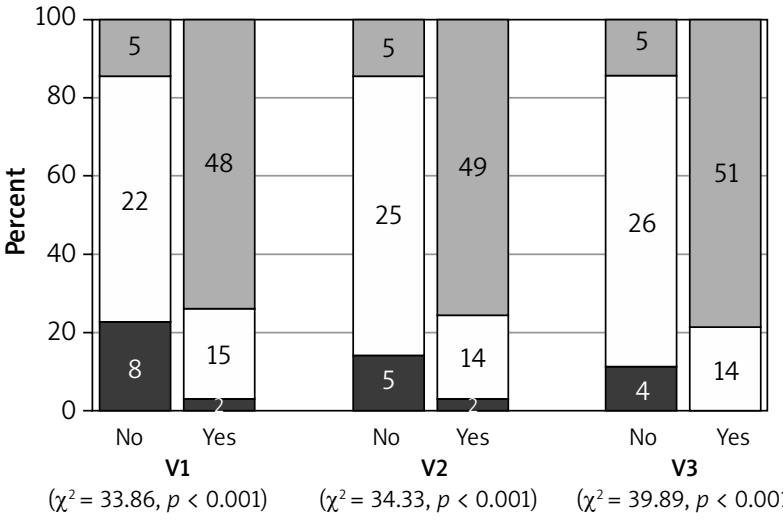

inhaled corticosteroids (ICS) only had better asthma control than those treated with a combination of inhaled corticosteroids (ICS) and LABAs. During the first follow-up, no significant differences were found in this respect. Neither were any significant differences found between allergen immunotherapy in youths with asthma and their overall ACT results in any of the three visits (V1: $p=0.4922 ; \mathrm{V} 2: p=0.9316 ; \mathrm{V} 3: p=0.6099)$. A sta-
B

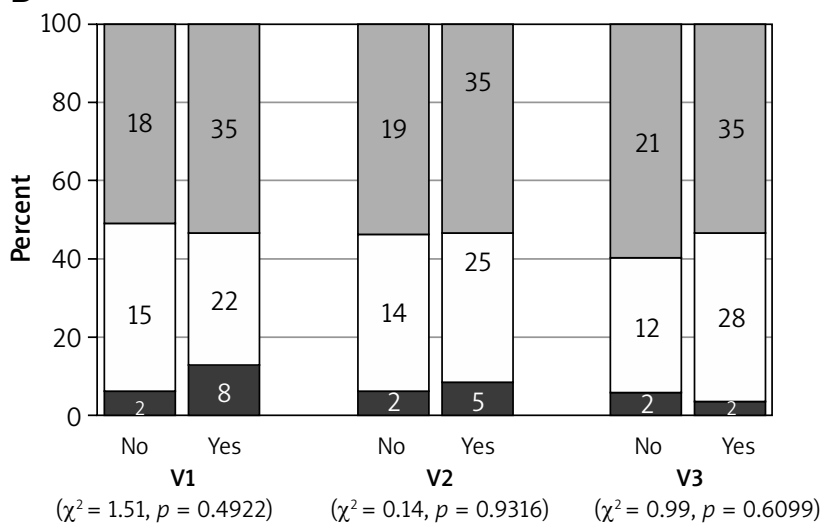

D

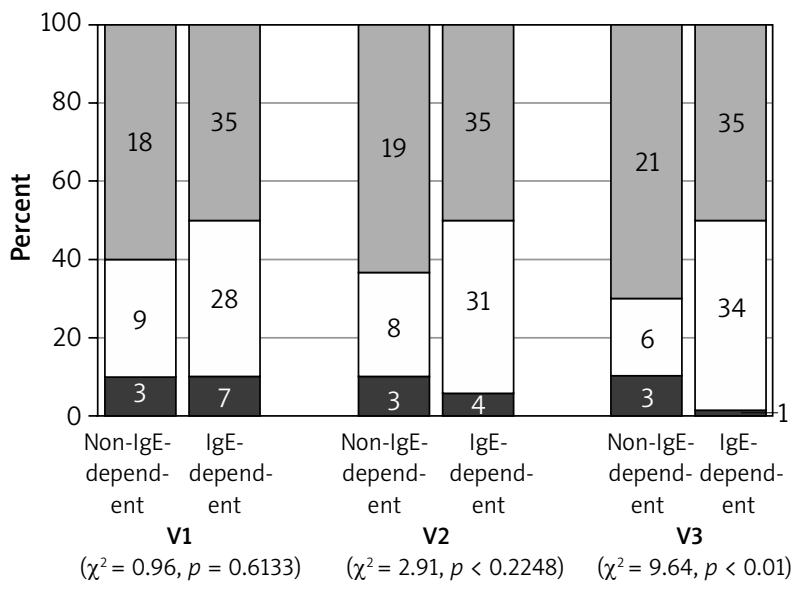

ACT

$\square<20 \quad \square 20-24 \quad \square 25$

Figure 2. Medical considerations ( $\mathbf{A}$ - treatment methods, B - allergen immunotherapy, C - concurrent allergic rhinitis and atopic dermatitis, D - asthma phenotype, E - family history of atopy) and asthma control assessed using the ACT

tistically significant $(p<0.001)$ correlation was shown between concurrent allergic diseases and the ACT results throughout the follow-up period. Patients reporting other allergic diseases had fully controlled asthma significantly more often.

The analysis of asthma phenotypes showed a statistically significant difference $(p<0.01)$ in ACT results at V3. Significantly more patients with non-lgE-dependent asth- 
ma than patients with IgE-dependent asthma achieved full asthma control $(p<0.01)$. In the first two follow-up visits, no statistically significant differences were found in this respect. The overall ACT results in all follow-up visits were at the same time significantly correlated $(p<0.001)$ with family history of allergies. Patients whose family history was positive for allergies had fully controlled asthma significantly more often than those with a negative family history for atopy.

\section{Discussion}

Achieving full asthma control through patient education and promotion of self-control is an important component in asthma treatment strategies. For an adolescent patient, achievement of full asthma control involves not only better health, but also, and more importantly, normal functioning at home, at school, and in the peer group [18-20].

GINA 2006 introduced a unified classification of asthma symptoms, defining three grades of asthma control: controlled asthma, partially controlled asthma, and uncontrolled asthma [21]. The ACT is a useful screening instrument enabling the identification of patients with uncontrolled disease [22-24]. Since 2008, GINA has been recommending the use of the Asthma Control Test (ACT'M) for asthma control assessment. It is particularly useful in long-term assessment, and its results are correlated with clinical parameters as evaluated by specialists, the results of pulmonary function tests, and the development of inflammatory processes [8].

The definition of asthma control proposed by GINA 2016 includes reduction of asthma symptoms during the day and/or night, unrestricted physical activity, exacerbation prevention, maintenance of normal pulmonary function, reduced use of $\beta$-agonists, and no medication side effects [25].

Asthma is a chronic inflammatory respiratory disease, whose effective treatment requires in-depth knowledge on the illness and ongoing cooperation with the therapeutic team $[3,8]$. Both the patient and their caregivers should be familiar with the symptoms, factors aggravating the course of the disease, and the appropriate measures for managing exacerbations. The subjective assessment of asthma using the ACT criteria should prompt the patient to consult a physician or to intensify treatment based on a specialist's recommendations. Therefore, the use of ACT contributes to improved patient knowledge and better cooperation with the physician. Waibel et al. [19] also highlight the educational value of the test, contributing to patient awareness of symptoms indicating exacerbation.

The present study showed that the result of the ACT, used as a standard procedure in all patient visits, was significant in subsequent diagnosis and treatment. In all three follow-ups, more than half of the youths obtained perfect scores, indicating fully controlled asthma, and approximately one third obtained satisfactory scores. In consecutive visits, the number of patients with good test results steadily increased, while the number of patients with uncontrolled asthma decreased steadily, which suggests an improvement in patient education, as well as good cooperation between medical personnel and the patients and their parents.

To make clinical evaluation objective, on every visit spirometry examination was conducted. Literature data show, however, that the Tiffeneau and $\mathrm{FEV}_{1} \%$ rate does not fully reflect the degree of asthma control in both adults and children. Even in children with uncontrolled asthma the parameters $\mathrm{FEV}_{1} / \mathrm{FVC} \%$ for a long time can be within the range of predicted values. On the other hand, it was demonstrated that Tiffeneau index $<60 \%$ is an independent predictor of asthma exacerbations, regardless of the degree of control of the disease $[8,26]$. While observing the mean $\mathrm{FEV}_{1} / \mathrm{FVC} \%$ on individual visits, it was found that they were within the normal and in most cases correlated with the subjective good asthma control in ACT test. In children with very good asthma control $(A C T=25)$, the highest value of $\mathrm{FEV}_{1} / \mathrm{FCV} \%$ was confirmed.

Sex may be a significant factor in subjectively assessed asthma control. Research points to the fact that female asthma patients report more symptoms, and that their negative experiences are more frequent and lasting. Weiner et al. suggest that the difference in subjective asthma control assessment between the sexes may be due to differences in perceived intensity of symptoms, as women and men react to episodes of dyspnea differently $[27,28]$. However, Dursun et al., comparing asthma selfcontrol in adult male and female patients, reported no statistically significant differences in ACT scores or clinical characteristics [20]. Meanwhile, in the present study, sex was a statistically significant factor differentiating asthma control assessed using the ACT, with worse asthma control at V1 and V2 in female patients. This can be due to factors specific to adolescence, including higher emotional lability in girls, which might have affected the ACT self-control scores [29].

Asthma has a variable course - hence the importance of ongoing clinical evaluation and adjustment of treatment, also affected by subjective factors reflecting asthma control. Patients' physical and psychological functioning, as well as disease self-control, typically worsen with age [30]. In the case of younger adolescents, parents/ caregivers typically participate in disease treatment and monitoring. Older youths typically show worse control of chronic disease [31]. This is due to their having gained more experience and authority, experiencing the need to become independent from their parents' authority, and developing an inclination for risky behaviors. However, in the present study, age was not a significant factor with regard to ACT scores.

Residence, as a demographic factor, may determine the accessibility of specialists. Patients in rural environ- 
ments typically experience more obstacles in access to medical care than those living in urban environments [32]. In the present study, nearly two-thirds of the group (65 patients) lived in rural areas. These patients were shown to have significantly worse asthma control, as assessed using the ACT, at the first follow-up, compared to urban residents.

Due to its complex etiopathogenesis, asthma management should be comprehensive, aiming to achieve full control of symptoms while minimizing the risk of adverse effects. Treatment standards recommend that all patients receive an individual treatment plan, in writing, including guidelines for managing exacerbations. The primary treatment, viewed as the most effective in terms of symptom control, respiratory inflammation prevention, pulmonary function maintenance, and patient lifestyle improvement, is to use inhaled corticosteroids (ICS) [21, 25]. Most patients were treated with ICS only, which resulted, in nearly all cases, in full or good control of asthma, as assessed by the ACT in all follow-up visits. LABAs are often used in combination with inhaled GCs as first-line therapy in chronic treatment of moderate and severe asthma in children and adolescents. Combination treatment may result in better symptom control than an increased dosage of ICS alone [27]. The present study did not corroborate the correlation, which is likely to be due to the disease severity observed in the patients studied.

One component of asthma management other than pharmaceutical treatment is allergen immunotherapy, modifying the course of atopic disease development [28]. Studies by other authors indicate that allergen immunotherapy in asthma significantly reduces symptoms and exacerbations. It also improves patients' functioning, physical performance, and quality of life [29]. In the present study, allergen immunotherapy did not significantly affect subjective asthma control as assessed by the ACT.

Epidemiological studies consistently report that allergic rhinitis and asthma are two atopic respiratory diseases constituting a substantial medical and socio-economic issue, due to their significant impact on patients' quality of life, restriction of daily activity, interference with sleep, and increased absence from school and work. Research conducted so far has demonstrated that treatment of rhinitis improves asthma control, while effective treatment of asthma positively affects the course of rhinitis [2].

Studies by other authors indicate that the presence of numerous allergy symptoms in various organs decreases asthma control $[13,29]$. In the present study, 75 patients experienced symptoms of other allergic diseases, including 58 cases of allergic rhinitis and 17 cases of atopic dermatitis, which is consistent with the literature data [3, 6]. Moreover, youths with concurrent allergic symptoms were found to have better ACT results in all follow-up visits analyzed, which may be due to the relatively small size of the study group, the large proportion of patients with a family history of atopy (which typically results in a trend for prevention, self-control, and chronic disease treatment in the family), and the large proportion of younger adolescents whose treatment is in most cases supervised by their parents.

Allergies involve genetic factors to a great extent. The familial background of asthma and allergies in the general population was the subject of multiple studies, which indicated that paternal factors contribute to the incidence of these diseases in children more than maternal ones [33]. In the present study, nearly two-thirds of the group (65 patients) had a family history of allergies. Moreover, youths with a positive family history for atopy significantly more often had fully controlled asthma than those with a negative family history. Chronic allergic disease in the family typically affects how other family members function, especially those who also have symptoms of the same or another allergic disease triggering adaptive mechanisms and promoting self-control [34, 35].

The positive result of ACT obtained by most patients in all the analyzed follow-up visits is the desired outcome of optimum asthma control, and affects youths' healthrelated behaviors, including improved perception of one's health, as well as their functioning in the family and social environment.

The present findings require further verification in a multi-center analysis, with a larger study group, as well as an evaluation of the actual effects of asthma patient education with regard to treatment monitoring.

\section{Conclusions}

Asthma control in adolescents differs by sex and residence. Concurrent allergies and family history of allergies improve asthma self-control in adolescents.

\section{Acknowledgments}

The authors thank Dorota Maksymczak MSc, nurse at the Allergy Clinic of the Independent Public Hospital in Lesko, Podkarpackie Province, Poland for organizational help in patients' examination.

\section{Conflict of interest}

The authors declare no conflict of interest.

\section{References}

1. Lai CK, Beasley R, Crane J, et al. Global variation in the prevalence and severity of asthma symptoms: phase three of the International Study of Asthma and Allergies in Childhood (ISSAC). Thorax 2009; 64: 476-83.

2. Bousquet J, Khaltaev N, Cruz AA, et al. Allergic Rhinitis and Its Impact on Asthma (ARIA 2008). Allergy 2008; 68: 8-160.

3. Mallol J, Crane J, Von Mutius E, et al. The International Study of Asthma And Allergies in Childhood (ISAAC) phase three: a global synthesis. Allergol Immunopathol (Madr) 2013; 41: 73-85. 
4. Sembajwe G, Cifuentes M, Tak SW, et al. National income, self-reported wheezing and asthma diagnosis from the World Health Survey. Eur Respir J 2010; 35: 279-83.

5. Samoliński B, Raciborski F, Tomaszewska A, et al. Epidemiology of allergic diseases in Poland - ECAP study. Allergy 2008; 63: 626-7.

6. Custowic A, Lazic N, Simpson A. Pediatric astma and development of atopy. Curr Opin Allergy Clin Immunol 2013; 13: 173-80.

7. Lis G, Bręborowicz A, Cichocka-Jarosz E, et al. Increase in bronchial astma incidence in school children in Krakow and Poznan - ISAAC study [Polish]. Pneumonol Alergol Pol 2003; 71: 336-43.

8. Wildhaber J, Carroll WD, Brand PL. Global impact of asthma on children and adolescents' daily lives: the room to breathe survey. Pediatr Pulmonol 2012; 47: 346-57.

9. Cope S, Ungar W, Glazier R. Socioeconomic factors and asthma control in children. Pediatr Pulmonol 2008; 43: 745-52.

10. Mousing CA, Lomborg K. Self-care 3 months after attending chronic obstructive pulmonary disease patient education: a qualitative descriptive analysis. Patient Prefer Adher 2012; 6: 19-25.

11. Zaihra T, Ernst P, Tamblyn R, Ahmed S. Tailoring interventions: identifying predictors of poor asthma control. Ann Allergy Asthma Immunol 2015; 114: 485-91.

12. Morrison D, Wyke S, Agur K, et al. Digital asthma self-management interventions: a systematic review. J Med Internet Res 2014; 16: e51.

13. Schatz M, Zeiger R, Yang SJ, et al. Change in asthma control over time: predictors and outcomes. J Allergy Clin Immunol Pract 2014; 2: 59-64.

14. Koshak E. Classification of asthma according to revised 2006 GINA: evaluation from severity to control. Ann Thorac Med 2007; 2: 45-6.

15. Nathan R, Sorkness C, Kosinski M, et al. Development of the Asthma Control Test: a survey for assessing asthma control. J Allergy Clin Immunol 2004; 113: 59-65.

16. Liu A, Zeiger R, Sorkness C, et al. The Childhood Asthma Control Test: retrospective determination and clinical validation of a cut point to identify children with very poorly controlled asthma. J Allergy Clin Immunol 2010; 126: 267-73.

17. Piacentini G, Peroni D, Bodini A, et al. Childhood Asthma Control Test and airway inflammation evaluation in asthmatic children. Allergy 2009; 64: 1753-7.

18. Redel H, Bateman E, Beker A, et al. A summary of the new GINA strategy: a roadmap to asthma control. Eur Respir 2015; 47: e1-18.

19. Waibel V, Ulmer H, Horak E. Assessing asthma control: symptom scores, GINA levels of asthma control, lung function and exhaled nitric oxide. Pediatr Pulmonol 2012; 47: 113-8.

20. Dursun A, Kurt O, Bayiz H, et al. Does gender affect asthma control in adult asthmatics? Chron Resp Dis 2014; 11: 83-7.

21. Reddel, H, Sawyer S, Everett P, et al. Asthma control in Australia: a cross-sectional web-based survey in a nationally representative population. Med J Aust 2015; 202: 492-8.

22. Rhee H, Belyea M, Ciurzynski S. Barriers to asthma selfmanagement in adolescents: relationships to psychosocial factors. Pediatr Pulmonol 2009; 44: 183-91.

23. Uchmanowicz I, Jankowska-Polańska B, Panaszek B, et al. Influence of socio-demographic factors on the quality of life of bronchial astma patients [Polish]. Alergol Info 2010; 5: 57-65.
24. Simões S, da Cunha S, Cruz A, et al. A community study of factors related to poorly controlled asthma among Brazilian urban children. PLoS One 2012; 7: e37050.

25. Chauhan B, Ducharme F. Addition to inhaled corticosteroids of long-acting beta 2-agonists versus anti-leukotrienes for chronic asthma (Review). Cochrane Database Syst Rev 2014; 1: 1-133.

26. Brand $P$, Duiverman E, Waalkens $H$, et al. Peak flow variation in childhood asthma: correlation with symptoms, airways obstruction, and hyperresponsiveness during long-term treatment with inhaled corticosteroids. Dutch CNSLD Study Group. Thorax 1999; 54: 103-7.

27. Xia Y, Kelton C, Xue L, et al. Safety of long-acting beta agonists and inhaled corticosteroids in children and adolescents with asthma. Ther Adv Drug Saf 2013; 4: 254-63.

28. Jutel M, Agache I, Bonini S, et al. International Consensus On (ICON) Allergy Immunotherapy (AIT). J Allergy Clin Immunol 2015; 136: 556-68.

29. Gniadek A, Malinowska-Lipień I, Solarz P, et al. Quality of life in patients with bronchial asthma treated with specific immunotherapy. Pielęg XXI w 2015; 2: 5-10.

30. Kim J, Lin S, Suarez-Cuervo C, et al. Allergen-specific immunotherapy for pediatric asthma and rhinoconjunctivitis: a systematic review. Pediatrics 2013; 131: e1-13.

31. Elkholy M, Khedr M, Halawa A, et al. Impact of allergic rhinitis on quality of life in patients with bronchial asthma. Int J Health Sci (Qassim) 2012; 6: 194-202.

32. Valerio $M$, Andreski $P$, Schoeni R, et al. Examining the association between childhood asthma and parent and grandparent asthma status: implications for practice. Clin Pediatr (Phila) 2010; 49: 535-41.

33. Lim R, Kobzik L, Dahl M. Risk for asthma in offspring of asthmatic mothers versus fathers: a meta-analysis. PLoS One 2010; 5: e10134.

34. Pietras T, Panek M, Witusik W, et al. Analysis of the correlation between level of anxiety, intensity of depression and bronchial asthma control. Post Dermatol Alergol 2011; 28: 15-22.

35. Orzechowska A, Gałecki P, Talarowska M, et al. Importance of the family in the course of bronchial asthma. Post Dermatol Alergol 2010; 26: 477-83. 